\title{
Calcium Indirectly Increases the Control Exerted by the Adenine Nucleotide Translocator over 2-Oxoglutarate Oxidation in Rat Heart Mitochondria
}

\begin{abstract}
Vida Mildaziene,*,1 Rasa Baniene,* Zita Nauciene,* Barbara M. Bakker,† Guy C. Brown,‡ Hans V. Westerhoff, $§$ and Boris N. Kholodenko\|

*Institute for Biomedical Research, Kaunas Medical Academy, 3007 Kaunas, Lithuania; †E. C. Slater Institute, BioCenter, University of Amsterdam, 1012 WX Amsterdam, The Netherlands; ‡Department of Biochemistry, University of Cambridge, Cambridge CB2 1TN, United Kingdom; §Department of Microbial Physiology, Faculty of Biology, Fre University, 1081 HV Amsterdam, The Netherlands; and \|A. N. Belozersky I nstitute of Physico-Chemi cal Biology, Moscow State University, 117234 Moscow, Russia
\end{abstract}

Received J uly 3, 1995, and in revised form September 20, 1995

The effect of calcium on the control exerted by the adenine nucleotide translocator over respiration in isolated heart mitochondria was investigated in order to determine whether calcium directly stimulates the translocator. At respiration rates intermediate between states 3 and $4, \mathrm{Ca}^{2+}$ is shown to increase the control over 2-oxoglutarate oxidation exerted by the adenine nucleotide translocator in rat heart mitochondria. This did not occur when succinate was the respiratory substrate, even though the control exerted by the translocator was substantial, indicating that $\mathrm{Ca}^{2+}$ does not have a direct effect on the adenine nucleotide translocator. $\mathrm{Ca}^{2+}$ increased the uncoupled oxidation rate of 2-oxoglutarate, but not succinate. Using the summation theorem for flux control, the effect of $\mathrm{Ca}^{2+}$ is explained by a shift of the control over respiration rate toward the adenine nucleotide translocator, from the respiratory chain, presumably as the result of the activation of the 2-oxoglutarate dehydrogenase complex. 1995 Academic Press, Inc.

Key Words: calcium; heart mitochondria; oxidative phosphorylation; 2-oxoglutarate dehydrogenase; adenine nucleotide translocator.

The control and regulation of mitochondrial respiration and ATP production are essential to cell function, and have been extensively studied [reviewed in (1-4)]. The extent to which the different components of oxida-

\footnotetext{
${ }^{1}$ To whom correspondence should be addressed at Institute for Biomedical Research, Kaunas Medical Academy, Eiveniu St. 4, 3007 Kaunas, Lithuania.
}

tive phosphorylation control the respiration rate in isolated mitochondria has been quantified using Metabolic Control Analysis [reviewed in $(5,6)$ ]. Control has been found to be distributed and shifts with conditions, but one of the major limiting components appears to be the adenine nucleotide translocator. The control exerted by the translocator is important because it determines the sensitivity of respiration to external adenine nucleotide levels, and thus the sensitivity of ATP supply to ATP utilization. Mitochondrial respiration and ATP production are thought to be physiologically regulated mainly by the levels of adenine nucleotides (ATP and ADP) and calcium. How these two types of regulation interact to determine rates may be important for an understanding of the overall regulation of ATP production, but has not been extensively studied.

In isolated mitochondria with an excess of substrate supply the control exerted by adenine nucleotide translocator has been found to be low in state 4 (no ATP turnover) and state 3 (maximal ATP turnover), but to be very high at intermediate rates of respiration (79). These intermediate rates of ATP turnover are probably the most physiologically relevant, since the heart in vivo would operate over this range. Thus, it would appear that over the physiological range the control resides mostly in the $A N T,{ }^{2}$ so that respiration would be sensitive to external nucleotide levels but not to other effectors. However, magnetic resonance spectroscopy measurements in perfused heart and heart in vivo

\footnotetext{
${ }^{2}$ Abbreviations used: ANT, adenine nucleotide translocator; EGTA, ethylene glycol bis( $\beta$-aminoethyl ether) $\mathrm{N}, \mathrm{N}$ '-tetraacetic acid; BSA, bovine serum albumin; MOPS, 4-morpholinepropanesulfonic acid.
} 
have indicated that the adenine nucleotide levels normally do not change significantly during the large changes in respiratory rate induced by a change in the heart work rate or adrenalin (1). Thus it has been suggested that in vivo heart respiration is not regulated by adenine nucleotide levels but by calcium levels activating matrix dehydrogenases (pyruvate dehydrogenase, isocitrate dehydrogenase, and 2-oxoglutarate dehydrogenase) which may control NADH supply to the respiratory chain (2). However, the physiological role of such regulation was unclear, particularly since at physiologically relevant rates of ATP turnover, control is apparently located mostly in the ANT and thus calcium should have no effect on respiration rate unless it acts directly on the ANT. It has also been suggested that calcium can directly stimulate the mitochondrial respiratory chain (2), the ATP synthase (10), and the ANT (11-13), but the evidence for such actions is relatively poor and indirect [see (3)].

In this paper we have investigated the influence of calcium on the control exerted by the ANT over respiration in physiologically relevant states of intermediate ATP turnover, low and high substrate supply, and at $37^{\circ} \mathrm{C}$. We show that the ANT does not have all the control in such states, and thus it is possible that other steps, including dehydrogenases, have significant control. Calcium causes large increases in respiration rate in such states when the substrate is 2-oxoglutarate, but not with succinate, and does so even when mitochondria are fully uncoupled. This suggests that calcium exerts its effects at the level of the dehydrogenases. Calcium increases the control exerted by the ANT on the 2-oxoglutarate oxidation rate, but has no effect when respiring on succinate even though the control coefficient is significant. This suggests that calcium has no significant direct kinetic effects on the ANT and it increases the control by ADP transport over 2-oxoglutarate oxidation without directly affecting the ANT.

\section{METHODS}

Mitochondria were isolated from hearts of several male Wistar rats. The hearts were cut and washed with ice-cold $0.9 \% \mathrm{KCl}$. Subsequently the tissue was washed in a buffer containing $160 \mathrm{~mm} \mathrm{KCl}$, $10 \mathrm{~mm} \mathrm{NaCl}, 20 \mathrm{~mm}$ Tris- $\mathrm{HCl}$, and $10 \mathrm{~mm}$ EGTA (pH 7.7) and then incubated for $5 \mathrm{~min}$ in the same buffer, also containing $0.25 \mathrm{mg}$ trypsin per gram tissue, homogenized gently (two times up and down) in a loose glass-Teflon homogenizer, and incubated for another 5 $\mathrm{min}$. After addition of trypsin inhibitor ( $2.5 \mathrm{mg} / \mathrm{g}$ tissue) and BSA (5 $\mathrm{mg} / \mathrm{g}$ tissue), it was homogenized again and centrifuged at $450 \mathrm{~g}$ (Sorvall RC-5B, SS-34 rotor). The supernatant was centrifuged at $6300 \mathrm{~g}$ and the obtained pellet was resuspended in a buffer containing 180 $\mathrm{mm} \mathrm{KCl}, 20 \mathrm{~mm}$ Tris- $\mathrm{HCl}$, and $3 \mathrm{~mm} \mathrm{EGTA} \mathrm{(pH} \mathrm{7.35)} \mathrm{to} \mathrm{approxi-}$ mately $50 \mathrm{mg} / \mathrm{ml}$ protein and stored on ice. The whole procedure was performed at $0^{\circ} \mathrm{C}$. The protein concentration was determined according to Lowry et al. (14).

Respiration of mitochondria was measured polarographically in a closed, stirred and thermostated 1-ml vessel at $37^{\circ} \mathrm{C}$ (Clark-type oxygen electrode) using 2-oxoglutarate ( 1,5 , or $10 \mathrm{~mm}$ ) or $5 \mathrm{~mm}$ succinate (plus $1 \mu \mathrm{m}$ rotenone), as oxidizable substrate, and $0.5 \mathrm{mg} / \mathrm{ml}$ mitochondria. Values of the concentrations of free $\mathrm{Ca}^{2+}$ and $\mathrm{Mg}^{2+}$ in the incubation media were stabilized by Ca/EGTA buffers and calculated using the stability constants and the program published by Fabiato and Fabiato (15). In all experiments with these buffers care was taken to adjust $\mathrm{pH}$ as precisely as possible to 7.2 at $37^{\circ} \mathrm{C}$ after addition of $\mathrm{Ca}^{2+}$ (either $5 \mathrm{~nm}$ free or $1 \mu \mathrm{M}$ free) and $\mathrm{Mg}^{2+}$ (1 mM free). All solutions added to the vessel were prepared so that they did not change $\mathrm{pH}$ on addition.

The state 3 respiration rate was measured in a medium containing

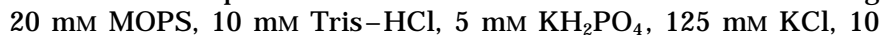
$\mathrm{mm} \mathrm{NaCl}, 3 \mathrm{~mm}$ EGTA, $2 \mathrm{~mm}$ ADP, and either $0.09 \mathrm{~mm}$ (5 nM free $\mathrm{Ca}^{2+}$ ) $\mathrm{CaCl}_{2}$ plus $1.5 \mathrm{~mm} \mathrm{MgCl}_{2}$ or $2.56 \mathrm{~mm}$ (1 $\mu \mathrm{M}$ free) $\mathrm{CaCl}_{2}$ plus $1.3 \mathrm{mM} \mathrm{MgCl}_{2}$. The uncoupled rate of succinate and 2-oxoglutarate oxidation was measured in the same medium in presence of $0.2 \mu \mathrm{M}$ CCCP. Due to the requirement for ADP of substrate level phosphorylation the uncoupled respiration with 2-oxoglutarate in the absence of external ADP or ATP was very low compared with the rate in state 3 and decreased to zero in a few minutes (16), in contrast to respiration on succinate. Therefore we used $1 \mu \mathrm{g}$ oligomycin/mg mitochondrial protein and $2 \mathrm{mM}$ ADP in addition to CCCP to measure the rate of uncoupled respiration with 2-oxoglutarate.

The $[A T P] /[A D P]$ ratio was clamped by adding excess of creatine phosphokinase $(0.1 \mathrm{mg} / \mathrm{ml}), 1 \mathrm{~mm}$ ATP, and varying the ratio of creatine and creatine phosphate, while their sum was kept constant at $50 \mathrm{~mm}$ (17). The intermediate rate of mitochondrial respiration constituting approximately $40-70 \%$ of the rate in state 3 was achieved in the medium containing $20 \mathrm{~mm}$ MOPS, $10 \mathrm{~mm}$ Tris $-\mathrm{HCl}$, $5 \mathrm{~mm} \mathrm{KH}_{2} \mathrm{PO}_{4}, 80 \mathrm{~mm} \mathrm{KCl}, 10 \mathrm{~mm} \mathrm{NaCl}, 3 \mathrm{~mm}$ EGTA, $1 \mathrm{~mm}$ dithiothreitol, $1 \mathrm{~mm}$ ATP, $30 \mathrm{~mm}$ creatine phosphate, $20 \mathrm{~mm}$ creatine (and either $0.09 \mathrm{mM} \mathrm{CaCl}_{2}$ plus $2.79 \mathrm{mM} \mathrm{MgCl}_{2}$ or $2.6 \mathrm{~mm} \mathrm{CaCl}_{2}$ plus 3.0 $\mathrm{mM} \mathrm{MgCl}_{2}$ ). For the maximal rate of respiration corresponding to the rate in state 3 the same medium was used except that creatine phosphate was absent and the concentration of creatine was $50 \mathrm{~mm}$ and of $\mathrm{KCl}$ was $110 \mathrm{~mm}\left(0.09 \mathrm{~mm} \mathrm{CaCl}\right.$ plus $2.3 \mathrm{~mm} \mathrm{MgCl}_{2}$ or 2.6 $\mathrm{mm} \mathrm{CaCl} 2$ plus $2.2 \mathrm{~mm} \mathrm{MgCl}_{2}$ ).

The control of the ANT on the respiratory rate was determined by titration with the noncompetitive, tight binding inhibitor carboxyatractyloside (18). The control coefficient was cal culated from thetitration curves (e.g., Fig. 1) using the equation

$$
C_{\text {ANT }}^{J}=\left(\frac{d J}{d l}\right)_{I=0} \cdot\left(\frac{I_{\max }}{J_{I=0}}\right),
$$

in which $J$ is the oxygen consumption rate, $(\mathrm{d} J / \mathrm{dl})$ is the initial slope of the titration curve, and I is the inhibitor concentration that inhibits the translocator completely (18).

\section{RESULTS}

The maximal stimulation of respiration rate with 2oxoglutarate in our experiments was observed at $1 \mu \mathrm{M}$ extramitochondrial free $\mathrm{Ca}^{2+}$. Therefore we chose to use two concentrations of external free calcium (5 nM and $1 \mu \mathrm{M}$ ) to study how calcium affects the distribution of the control of mitochondrial respiration among the processes involved. We focused on control exerted by adenine nucleotide transport across the inner membrane and addressed the question how much the extent to which that process controls respiration in the intermediate range of rates depended on the free calcium concentration. The amount of control exerted by the ANT was determined by titration of 2-oxoglutarate oxidation in isolated rat heart mitochondria with the tight binding inhibitor carboxyatractiloside (18). The extramitochondrial phosphorylation potential was clamped 


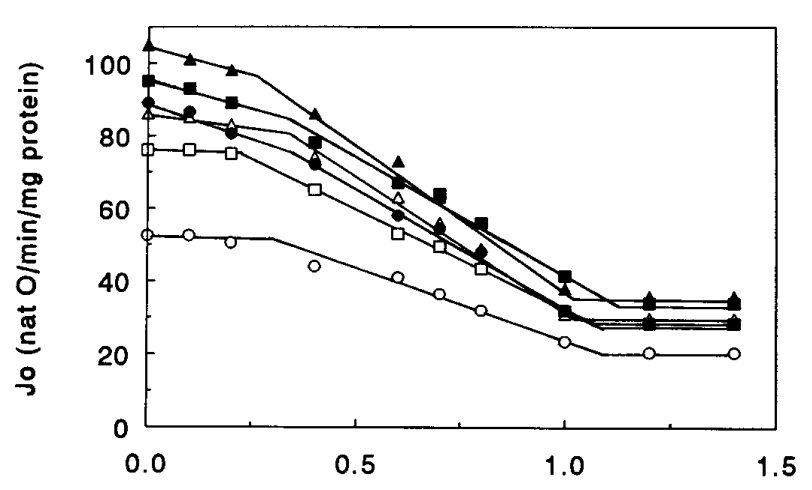

carboxyatractyloside ( $\mathrm{nmol} / \mathrm{mg}$ protein)

FIG. 1. Carboxyatractyloside titration of mitochondrial respiration with 2-oxoglutarate at the intermediate range of rates between state 3 and state 4 at different external free $\mathrm{Ca}^{2+}$ concentrations. The intermediate rate of mitochondrial respiration $\left(\mathrm{J}_{0}\right)$ between the rates in state 4 and state 3 was set by $1 \mathrm{~mm}$ ATP, excess of creatine kinase, and the ratio of creatine phosphate/creatine $30 / 20(\mathrm{~mm} / \mathrm{mm})$ in the medium. Each point on the titration curves represents the mean value of three or more repetitive runs of a typical experiment (the standard deviations are smaller than the representation of the points). Similar results were obtained in four other experiments. $\bigcirc$, $\bullet, 1 \mathrm{~mm}$; $\square, \mathbf{\square}, 5 \mathrm{~mm} ; \triangle, \boldsymbol{\Delta}, 10 \mathrm{~mm}$ 2-oxoglutarate. $\bigcirc, \square, \triangle, 5 \mathrm{~nm}$; $\bullet, \mathbf{\square}, \mathbf{\Delta}, 1 \mu \mathrm{M}$ free external $\mathrm{Ca}^{2+}$.

(by addition of ATP and excess of creatine kinase, creatine, and creatine phosphate) to a level that sustained a respiration rate approximately half (40-70\%) its maximum (state 3). Figure 1 gives the results of a typical inhibitor titration experiment at three different concentrations of 2-oxoglutarate $(1,5$, and $10 \mathrm{~mm})$. The stimulation of respiration by $\mathrm{Ca}^{2+}$ decreased with an increase in the concentration of 2-oxoglutarate (in the experiment presented the stimulation was 71,27 , and $20 \%$, respectively). Calcium increased the dependence of the respiration rate on the ANT at all substrate concentrations used. Table I confirms that the ANT's share of the control of 2-oxoglutarate oxidation rises substantially in the presence of calcium at the intermediate rates. However, carboxyatractyloside titrations of respiration were sigmoidal at the maximal rates of 2-oxoglutarate oxidation (corresponding to state 3 ) both at 5 $\mathrm{nm}$ and at $1 \mu \mathrm{m}$ free calcium. This implies that adenine nucleotide transport does not control the maximal rate, i.e., the control coefficient of the ANT is zero (Table I). The stimulation of respiration by calcium in that set of experiments was $72 \pm 6 \%$ at the intermediate rate of respiration with $1 \mathrm{~mm}$ 2-oxoglutarate.

In parallel the same preparations of mitochondria were used to determine the influence of calcium on succinate oxidation and the control coefficient of the ANT over the intermediate rate of respiration with succinate. Figure 2 shows that calcium had no effect on the intermediate rate of succinate oxidation, and that it did not change the sl ope of carboxyatractyl oside titration curve, giving the same value of the control coeffi- cient of the ANT (Table II). This result indicates that calcium does not directly stimulate the ANT.

In order to test whether calcium stimulates the oxidative system rather than the phosphorylation system we uncoupled respiration from phosphorylation by adding the protonophore CCCP [plus oligomycin and adenine nucleotides, to meet the requirement of substrate level phosphorylation for ADP (16)], and then investigated whether $\mathrm{Ca}^{2+}$ could still stimulate 2-oxoglutarate respiration. We measured the initial rates of respiration after addition of CCCP to the mitochondria previously preincubated for $3 \mathrm{~min}$ with substrate, oligomycin, ADP, and different calcium concentrations. Table III shows that calcium stimulated uncoupled respiration with $1 \mathrm{~mm}$ 2-oxoglutarate. This can be explained by the activation of the 2-oxoglutarate dehydrogenase complex by $\mathrm{Ca}^{2+}(2,19)$. On the other hand, $\mathrm{Ca}^{2+}$ did not affect succinate respiration in the presence of the uncoupler (Table III). $\mathrm{Ca}^{2+}$ also stimulated the rate of 2-oxoglutarate (but not succinate) oxidation in state 3 (excess ADP, legend to Table III) and the extent of stimulation was dependent on concentration of 2-oxoglutarate $-+67,+41$, and $+23 \%$ with 1,5 , and $10 \mathrm{~mm}$, respectively $(n=5)$. State 4 respiration (i.e., respiration in the absence of ADP) of succinate was not affected by calcium (130 \pm 6.2 and $131 \pm 9.0$ natO/min/ mg mitochondrial protein at $5 \mathrm{~nm}$ and $1 \mu \mathrm{M} \mathrm{Ca}$, respectively), but in the case of $1 \mathrm{~mm} 2$-oxoglutarate it was increased from $27.4 \pm 2.2$ to $40.2 \pm 3.2$ natO $/ \mathrm{min} / \mathrm{mg}$ mitochondrial protein ( $n=4, P<0.05$ ), most probably reflecting the increased proton leak due to some rise in the membrane potential after activation of 2-oxoglutar-

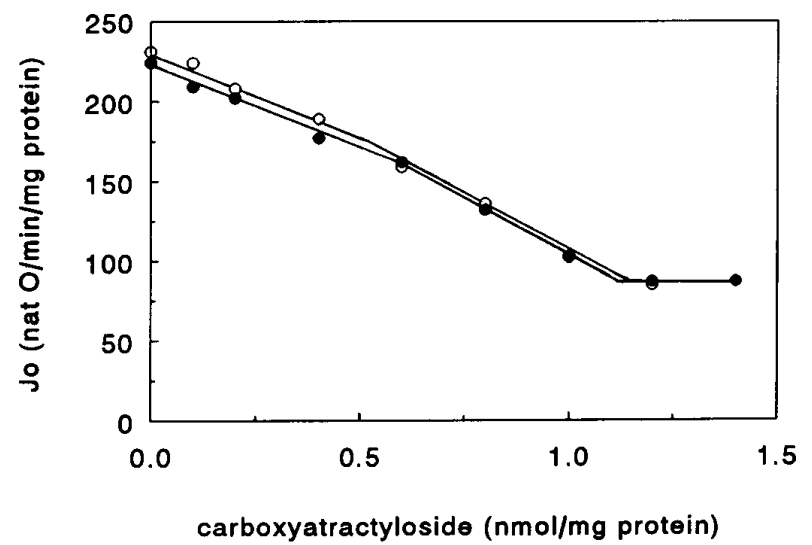

FIG. 2. Carboxyatractyloside titration of mitochondrial respiration with $5 \mathrm{~mm}$ succinate at the intermediate range of rates between state 3 and state 4 at different external free $\mathrm{Ca}^{2+}$. The intermediate rate of mitochondrial respiration $\left(\mathrm{J}_{0}\right)$ between the rates in state 4 and state 3 was set by $1 \mathrm{~mm}$ ATP, excess of creatine kinase, and the ratio of creatine phosphate/creatine $30 / 20(\mathrm{~mm} / \mathrm{mm})$ in the medium. Each point on the titration curves represents the mean value of three or more repetitive runs of a typical experiment (the standard deviations are smaller than the representation of the points). Similar results were obtained in three other experiments. $\bigcirc, 5 \mathrm{~nm} ; \bullet, 1 \mu \mathrm{M}$ free external $\mathrm{Ca}^{2+}$. 
TABLE I

Control Coefficient of Adenine Nudeotide Translocator $\left(\mathrm{C}_{\mathrm{ANT}}\right)$ over Intermediate and Maximal Rate of 2-Oxoglutarate Oxidation by Heart Mitochondria at Different Concentrations of External Free $\mathrm{Ca}^{2+}$

\begin{tabular}{|c|c|c|c|c|c|c|}
\hline \multirow{2}{*}{$\frac{\text { 2-Oxoglutarate: }}{\mathrm{Ca}^{2+}:}$} & \multicolumn{2}{|c|}{$1 \mathrm{~mm}$} & \multicolumn{2}{|c|}{$5 \mathrm{~mm}$} & \multicolumn{2}{|c|}{$10 \mathrm{~mm}$} \\
\hline & $5 \mathrm{~nm}$ & $1 \mu \mathrm{M}$ & $5 \mathrm{~nm}$ & $1 \mu \mathrm{M}$ & $5 \mathrm{~nm}$ & $1 \mu \mathrm{M}$ \\
\hline \multicolumn{7}{|l|}{$\mathrm{C}_{\mathrm{ANT}}$ at maximal } \\
\hline rate & $\begin{array}{c}0 \\
(3)\end{array}$ & $\begin{array}{c}0 \\
(3)\end{array}$ & $\begin{array}{c}0 \\
(3)\end{array}$ & $\begin{array}{c}0 \\
(3)\end{array}$ & $\begin{array}{c}0 \\
(3)\end{array}$ & $\begin{array}{c}0 \\
(3)\end{array}$ \\
\hline $\begin{array}{l}\mathrm{C}_{\mathrm{ANT}} \text { at intermediate } \\
\text { rate }\end{array}$ & $\begin{array}{c}0.06 \pm 0.06 \\
(6)\end{array}$ & $\begin{array}{c}0.53^{*} \pm 0.03 \\
(6) \\
\mathrm{P}<0.01\end{array}$ & $\begin{array}{c}0.07 \pm 0.07 \\
(5)\end{array}$ & $\begin{array}{c}0.57 * \pm 0.08 \\
\quad(5) \\
P<0.001\end{array}$ & $0.30 \pm 0.08$ & $\begin{array}{c}0.63^{*} \pm 0.06 \\
(5) \\
P<0.05\end{array}$ \\
\hline
\end{tabular}

Note The intermediate rate of 2-oxoglutarate oxidation between the rates in state 4 and state 3 was set by 1 mM ATP, excess of creatine kinase, and the ratio of creatine phosphate/creatine 30/20 (mm/mm) in the medium, and the maximal rate by ratio 0/50 (see $\mathrm{Methods).} \mathrm{The}$ maximal rate of respiration with $1 \mathrm{~mm}$ 2-oxoglutarate was $126 \pm 9$ and $202 \pm 25$, with $5 \mathrm{~mm} 173 \pm 20$ and $224 \pm 23$, with $10 \mathrm{~mm} 220 \pm$ 20 and $276 \pm 30$ natO/min/mg mitochondrial protein, at $5 \mathrm{~nm}$ and $1 \mu \mathrm{M} \mathrm{Ca}{ }^{2+}$, respectively. The intermediate rate of respiration in the same experiments with $1 \mathrm{~mm}$ 2-oxoglutarate was $82 \pm 10$ and $141 \pm 15$, with $5 \mathrm{~mm} 106 \pm 17$ and $143 \pm 20$, with 10 mm $124 \pm 17$ and $153 \pm 20$ nat0/min/mg mitochondrial protein, at $5 \mathrm{~nm}$ and $1 \mu \mathrm{M} \mathrm{Ca}{ }^{2+}$, respectively. The number of experiments is indicated in parenthesis. *Statistically significant difference of control coefficient at $5 \mathrm{nM}$ and $1 \mu \mathrm{M} \mathrm{Ca}^{2+}$.

ate dehydrogenase. However, this difference in state 4 at different $\mathrm{Ca}^{2+}$ concentrations was less in the medium with creatine and creatine phosphate.

The control exerted by the ANT on mitochondrial respiration depends on the external ATP/ADP ratio (7). When the latter is clamped, as in the present experiments, the control drops at low ATP/ADP ratios, compared to intermediate ATP/ADP ratios $(9,17,20)$. Accordingly at all concentrations of 2-oxoglutarate we found no significant control by the ANT over the maximal rate in the present experiments (Table I). I ncreasing the 2-oxoglutarate concentration from 1 to $5 \mathrm{~mm}$ substantially increased the respiratory rate in all preparations of mitochondria. That was, however, not always the case when increasing from 5 to $10 \mathrm{~mm}$. Like increased $\mathrm{Ca}^{2+}$ concentration, an increased 2-oxoglutarate concentration might indirectly increase the control exerted by the ANT on respiration. Table I shows that this is indeed the case in the intermediate range of rates: in the absence of $\mathrm{Ca}^{2+}$ the control by the ANT

\section{TABLE II}

The Rate of Succinate Oxidation $\left(\mathrm{O}_{\mathrm{o}}\right.$ ) and Control Coefficient of Adenine Nucleotide Translocator $\left(C_{A N T}\right)$ in the Intermediate State between State 4 and State 3 at Different External $\mathrm{Ca}^{2+}$ Concentrations

\begin{tabular}{lcc}
\hline $\mathrm{Ca}^{2+}$ & $5 \mathrm{nM}$ & $1 \mu \mathrm{M}$ \\
\hline $\mathrm{J}_{0}$ & $319 \pm 39$ & $322 \pm 39$ \\
$\mathrm{C}_{\mathrm{ANT}}$ & $0.435 \pm 0.05$ & $0.445 \pm 0.04$ \\
\hline
\end{tabular}

Note The average \pm SE of four experiments is presented. The rate of respiration in state 3 was $595 \pm 50$ natO/min/mg mitochondrial protein, $\mathrm{RCl} 3.8 \pm 0.1$. increased substantially when the substrate concentration increased from 5 to $10 \mathrm{~mm}$, and the same tendency is observed with $\mathrm{Ca}^{2+}$. This finding serves as a positive control for the possibility that one can increase the control by the ANT by activating the 2-oxoglutarate complex.

\section{DISCUSSION}

Various effects of calcium on mitochondrial oxidative phosphorylation have been reported (reviewed in 4). At concentrations higher than used in the present study, the simultaneous operation of various $\mathrm{Ca}^{2+}$ transport systems leads to swelling and uncoupling. At the concentrations below $1 \mu \mathrm{M}$, state 4 respiration (i.e., respiration in the absence of ADP) on succinate was unaffected by calcium, indicating that these concentrations did not directly affect proton permeability. Calcium also had no effect on succinate oxidation in state 3 , in

\section{TABLE III}

The Uncoupled Rate of Respiration with 2-Oxoglutarate and Succinate at Different External $\mathrm{Ca}^{2+}$ Concentrations

\begin{tabular}{ccc}
\hline $\mathrm{Ca}^{2+}$ & $5 \mathrm{nM}$ & $1 \mu \mathrm{M}$ \\
\hline $1 \mathrm{~mm}$ 2-oxoglutarate & $111 \pm 17$ & $173 \pm 19^{*}$ \\
$5 \mathrm{~mm}$ succinate & $430 \pm 11$ & $432 \pm 17$ \\
\hline
\end{tabular}

Note Averages \pm SE of five experiments with 2-oxoglutarate and four experiments with succinate are presented. State 3 respiration rate in that set of experiments was $118 \pm 6$ and $192 \pm 12$ with 1 $\mathrm{mm}$ 2-oxoglutarate, and $436 \pm 17$ and $446 \pm 11$ natO $/ \mathrm{min} / \mathrm{mg}$ mitochondrial protein with $5 \mathrm{~mm}$ succinate at $5 \mathrm{~nm}$ and $1 \mu \mathrm{M} \mathrm{Ca}{ }^{2+}$, respectively. $*$ Statistically significant effect of $\mathrm{Ca}^{2+}(\mathrm{P}<0.01)$. 
the state intermediate between state 3 and 4 , and in uncoupled mitochondria, suggesting that calcium had no direct effect on the respiratory chain or the adenine nucleotide translocator. The present paper has shown that $\mathrm{Ca}^{2+}$ affects the extent to which ATP/ADP transport across the inner mitochondrial membrane controls the mitochondrial oxidation of 2-oxoglutarate. One specific implication is that the response of the rate at which mitochondria synthesize ATP to a change in demand for ATP is enhanced by calcium ions. This phenomenon is strong at intermediate workloads and low concentration of 2-oxoglutarate, but absent when succinate is the electron donor for respiration.

A potentially more general implication is that an agent may modify the control exerted by an enzyme without directly affecting that enzyme. Indeed, we showed, for both $\mathrm{Ca}^{2+}$ and 2-oxoglutarate, that they affected the control by the ANT while acting at the level of 2-oxoglutarate dehydrogenase. Perhaps the best way to rational ize this phenomenon is to involve the control principles derived by Metabolic Control Analysis. It has shown that the flux control exerted by an enzyme is not just a kinetic property of that enzyme, but a property of the entire system (21). This is illustrated most cogently by the summation theorem which states that the control exerted on a flux must add up to 1 :

$$
C_{1}^{\jmath}+C_{2}^{\jmath}+C_{3}^{\jmath}+\cdots+C_{n}^{\jmath}=1,
$$

where the summation is over all enzymes in the pathway. Thus, activation of one enzyme with concomitant reduction of its control, will have the tendency to increase the control of some other enzymes in the pathway. This principle is quite general and it remains to be seen to what extent it accounts for observed pleiotropic effects of various modulators of metabolic fluxes, such as calcium.

Moreno-Sanchez and colleagues (11-13) found that in state 3 (with excess of ADP) calcium caused the control exerted by the ANT to decrease, from which they concluded that calcium may directly stimulatetheANT as well as other components. However, the decrease in the control coefficient of the enzyme does not always mean that the enzyme is activated. Moreover, it does not follow that activation of an enzyme will necessarily lead to the decrease of its control coefficient.
The present article suggests that the observed effect of calcium on the flux control by the ANT may be explained on the basis of a stimulatory effect of calcium on 2-oxoglutarate dehydrogenase.

\section{ACKNOWLEDGMENTS}

This study was supported by the Netherlands Organization for Scientific Research (NWO) and the UNESCO, Royal Society (UK), and International Science Foundation (U.S.A.).

\section{REFERENCES}

1. Heineman, F. W., and Balaban, R. S. (1990) Annu. Rev. Physiol. 52, 523- 542.

2. McCormack, J. G., Halestrap, A. P., and Denton, R. M. (1990) Physiol. Rev. 52, 451- 466.

3. Brown, G. C. (1992) Biochem. J . 284, 1- 13.

4. Gunter, T. A., Gunter, K. K., Shey-Shing, S., and Gavin, C. E. (1994) Am. J . Physiol. 267, C313-C339.

5. Westerhoff, H. V., and Van Dam, K. (1987) Thermodynamics and Control of F ree-E nergy Transduction, Elsevier, Amsterdam.

6. Fell, D. A. (1992) Biochem. J . 286, 313-330.

7. Wanders, R. J. A., Groen, A. K., Van Roermund, C. W. T., and Tager, J . M. (1984) Eur. J . Biochem. 142, 417- 424.

8. Hafner, R. P., Brown, G. C., and Brand, M. D. (1990) Eur. J . Biochem. 188, 313-319.

9. Mildaziene, V., Borutaite, V., Katiliute, Z., Petroliunaite, R., I vanoviene, L., Toleikis, A., Kholodenko, B. (1994) in Modern Trends in Biothermokinetics (Schuster, S., Rigoulet, M., Ouhabi, R., and Mazat, J .-P., Eds.), pp. 347-350, Plenum, New York.

10. Harris, D. A., and Das, A. M. (1991) Biochem. J . 280, 561- 573.

11. Moreno-Sanchez, R. (1985) J . Biol. Chem. 23, 12554- 12560.

12. Moreno-Sanchez, R., Hogue, B. A., and Hansford, R. G. (1990) Biochem. J . 268, 421- 428.

13. Moreno-Sanchez, R., Devars, S., Lopez-Gomez, F., Uribe, A., and Corona, N. (1991) Biochem. Biophys. Acta 1060, 284- 292.

14. Lowry, O. H., Rosebrough, N. J ., Fait, A. L., and Randall, R. J . (1951) J . Biol. Chem. 193, 265- 275.

15. Fabiato, A., and Fabiato, F. (1979) J . Physiol . (Paris) 75, 463505.

16. Chappell, J . B., and Greville, G. D. (1961) Nature 190, 502- 504.

17. Kholodenko, B. N., Zilinskiene, V., Borutaite, V., I vanoviene, L., Toleikis, A., and Praskevicius, A. (1987) FEBS Lett. 233, 247250.

18. Groen, A. K., Wanders, R. J . A., Westerhoff, H. V., Van der Meer, R., and Tager, J. M. (1982) J . Biol. Chem. 257, 2754- 2757.

19. McCormack, J. G., and Denton, R. M. (1979) Biochem. J . 180, 533- 544.

20. Kholodenko, B. N. (1984) J . Theor. Biol. 107, 179- 188.

21. Kacser, H., and Burns, J . (1973) Symp. Soc. Exp. Biol. 27, 65104. 